\title{
Explorando uma Prática Humanizada em Terapia Ocupacional: Implantação de um Instrumento de Avaliação Durante a Internação em Hospital de Média Complexidade
}

\author{
Toldrá, Rosé Colom; Batista, Marina Picazzio Perez; Souto, Ana Cristina Fagundes; \\ Freitas, Dionne do Carmo Araújo; Etyoshioka, Eliani Tiemi; Almeida, Maria Helena \\ Morgani de \\ Universidade de São Paulo Departamento de Fisioterapia, Fonoaudiologia e Terapia Ocupacional da \\ Faculdade de Medicina — rosetoldra@usp.br
}

Introdução: em ambiente hospitalar, a avaliação de Terapia Ocupacional norteada pela integralidade do cuidado deve favorecer o desenvolvimento de estratégias para que o equipe possa compreender e intervir nas necessidades singulares do sujeito. Objetivo: o presente trabalho apresenta o instrumento de avaliação construída para utilização pelos residentes de Terapia Ocupacional no atendimento a adultos internados em uma enfermaria de Clínica Médica de um hospital de atenção secundária no município de São Paulo. Método: a construção do instrumento, a partir de uma perspectiva biopsicossocial, buscou abordar diversos aspectos envolvidos no processo de internação, compreendendo-o como um momento vivenciado de modo singular e que envolve condições complexas, permeadas pela cultura, valores e crenças do sujeito. Ainda, levou-se em consideração que a internação pode ser vivenciada como uma experiência de ruptura na rotina da pessoa, afastamento temporário de seu convívio familiar e social, podendo também implicar em intervenções invasivas, alterações funcionais, dor, quadro de dependência, falta de privacidade, alteração de papéis ocupacionais e contato com aspectos relativos à finitude. Resultados: o instrumento construído constitui-se de questões abertas, que buscaram em seu conjunto: a) proporcionar condições para a pessoa de expressar seus temores, percepções, expectativas, dúvidas e identificar outros fatores que repercutem em sua relação com a hospitalização, o diagnóstico e os procedimentos hospitalares; b) compreender os impactos gerados pela hospitalização, para o sujeito e seus cuidadores, em sua relação com a internação, com a alta hospitalar, com a equipe e com os demais sujeitos internados; c) conhecer os projetos e atividades prévias à internação e que devido à interrupção, o sujeito demonstre desejo de dar continuidade, bem como projetos que deseja realizar; d) proporcionar escuta às necessidades, interesses e dificuldades dos sujeitos e familiares; e) levantar as atividades desempenhadas pelo sujeito, tanto em sua rotina extra quanto intra-hospitalar, identificando dificuldades, potencialidades, desejos e expectativas, bem como aspectos físicos, sensoriais, cognitivos, ambientais e emocionais que influenciam em sua realização com independência e autonomia. em caso de necessidade, os residentes utilizam avaliações funcionais específicas, complementares à entrevista de avaliação; f) identificar a Unidade Básica de referência do sujeito e os serviços pelos quais é atendido, de modo a conhecer o fluxo de referência e contrarreferência da linha de cuidados ao sujeito. Conclusões: a diversidade de aspectos abordados na avaliação permite em seu conjunto a sensibilização dos residentes para a complexidade envolvida na humanização do atendimento ao sujeito. o momento de avaliação, quando norteado pelo protagonismo do sujeito, permite o compartilhamento e corresponsabilização no processo de produção de saúde.

Toldrá, Rosé Colom; Batista, Marina Picazzio Perez; Souto, Ana Cristina Fagundes; Freitas, Dionne do Carmo Araújo; Etyoshioka, Eliani Tiemi; Almeida, Maria Helena Morgani de. Explorando uma Prática Humanizada em Terapia Ocupacional: Implantação de um Instrumento de Avaliação Durante a Internação em Hospital de Média Complexidade. In: Anais do Congresso Internacional de Humanidades \& Humanização em Saúde [= Blucher Medical Proceedings, num.2, vol.1]. São Paulo: Editora Blucher, 2014. ISSN 2357-7282

DOI 10.5151/medpro-cihhs-10501 